\title{
FORMULATION AND EVALUATION OF STABILITY OF THAI PURPLE RICE BRAN-BASED COSMETIC PRODUCTS
}

\section{CHAIYAVAT CHAIYASUT ${ }^{1}$, PERIYANAINA KESIKA ${ }^{1}$, POOMCHON SAKDAKAMPANAT ${ }^{1}$, SARTJIN PEERAJAN $^{2}$, BHAGAVATHI SUNDARAM SIVAMARUTHI ${ }^{1 *}$}

\author{
${ }^{1}$ Innovation Center for Holistic Health, Nutraceuticals and Cosmeceuticals, Faculty of Pharmacy, Chiang Mai University, Chiang Mai 50200, \\ Thailand. ${ }^{2}$ Health Innovation Institute, Chiang Mai 50230. Email: Thailand. sivasgene@gmail.com
}

Received: 17 August 2017, Revised and Accepted: 29 September 2017

ABSTRACT

Objective: The rice bran (RB) phytochemicals are known for several pharmacological properties. The current study was aimed to extract the active principles from Thai purple RB, formulate the cosmetic products, and evaluate the physical property and stability of the products.

Methods: Purple RB was extracted using $80 \%$ ethanol, and total phenolic and anthocyanin contents were measured using high-pressure liquid chromatography (HPLC) and spectrophotometric methods. Rice bran oil (RBO) was obtained by cold press method, and oryzanol content was determined using HPLC. The antioxidant capacity of RBO and purple rice bran extract (PRE) was assessed using spectrophotometric methods. The cosmetic products were formulated with PRE and fermented and distilled purple rice solution (FDPRS). RBO was also used as an ingredient in the formulation of solid soap. The stability of the formulations was also assessed. The heavy metal and microbial contamination were determined using atomic absorption spectrometry and plating assay, respectively.

Results: The yield of PRE and RBO was 0.92 and 1.62\%, respectively. The total phenolic and anthocyanin content of PRE was $305.30 \pm 6.15$ mg gallic acid/g of extract and $877.33 \pm 87.73 \mathrm{mg}$ cyanidin chloride/g of extract, respectively. Oryzanol content of RBO was $6.33 \pm 0.09 \mathrm{mg} / \mathrm{g}$ of RBO. RBO, PRE, and FDPRS exhibited high antioxidant capacity. The cosmetic formulations were observed to be physically stable in the heat-cool cycle, and the stability of the active compounds was not affected while stored at $30^{\circ} \mathrm{C}$ for 2 months. The storage temperature affected the phenolic compounds present in the cosmetic formulations, especially at $45^{\circ} \mathrm{C}$. There was no significant decrease in oryzanol content of soap formulation. All the formulations were free from microbial and heavy metal contamination.

Conclusion: The RB phytochemical-based cosmetic products are rich in antioxidants, stable, and free from heavy metals and microbial contamination, and further fine-tuning of the formulation may achieve the market quality.

Keywords: Antioxidants, Cosmetic, Thai purple rice, Rice bran, Rice bran oil, Heavy metals.

(C) 2018 The Authors. Published by Innovare Academic Sciences Pvt Ltd. This is an open access article under the CC BY license (http://creativecommons. org/licenses/by/4. 0/) DOI: http://dx.doi.org/10.22159/ajpcr.2018.v11i1.22073

\section{INTRODUCTION}

The cosmetic industries are massive, exclusively consumer-based business with the market value of about $\$ 11.7$ billion as on 2016 . Cosmetics are used to improve the physical appearance and prevent the natural processes that influence the exterior look of the human being, primarily, used against the aging process. Several cosmetic products claim that they have appropriate positive effects on the skin such as antiaging and skin tightening. The scientific reports and evidence about the prime compounds used in the cosmetic preparations are limited and capricious. Many cosmeceutical companies claim that they have used natural ingredients in their products [1].

Rice bran (RB) phytochemicals (flavonoids, phenolics, tannins, sterols, tocols, $\gamma$-oryzanols, and amino acids) are known for several pharmacological properties such as antioxidant [2], anti-colitis [3], anticancer, antitumor, antimutagenic [4], antidiabetes [5], ocular impairment [6], anti-aging [7], and anti-inflammatory [8].

Studies reported that rice bran extracts (RBE) are potent hair-growth inducer through 5-alpha-reductase inhibition without exhibiting any adverse effects $[9,10]$. Rice bran oil (RBO) is rich in unsaturated fatty acids (oleic, linoleic, and $\alpha$-linolenic acids) and saturated fatty acids (palmitic and stearic acids). RBOs are used in the cosmetic products, mainly in sunscreen, antiaging, and skin-lightening products, because of its bioactivities and moisturizing properties on the skin [11-15]. Thai-pigmented rice has been reported as an active ingredient in cosmetics, pharmaceuticals, and functional foods [16]. The cosmetic surfactant derived from rice was proved as a potent emulsifier for making cosmetic products which consist of fatty ingredients [15].

Pengkumsri et al. [2] reported the phenolic acid content of RB (RB of black, red, and brown rice) extracted using $80 \%$ ethanol. Daud et al. [17] studied the impact of different solvent (hexane, ethanol, and methanol) extraction methods on total phenolic content and antioxidant properties of RBO of different rice varieties. Daud et al. [17] stated that total phenolic content and antioxidant activity depend on both solvent extraction method and RB types. Sukrasno et al. [18] reported that ethanol extract of black RB exhibited highest phytochemical content, namely, carotenoid, flavonoid, and phenolic content, and antioxidant activity when compared to that of the other extraction methods.

Pengkumsri et al. [19] reported the influence of extraction methods in the recovery of oryzanol and tocols in RBO of black, red, and brown rice. Hexane extraction showed a maximum recovery of oryzanol and tocols compared to that of the other extraction methods including cold press extraction method [19]. Cold press extraction was considered as a solvent-free and environmentally safe extraction method [20]. In the present study, the extracted RBO was used for the cosmetic formulation (solid soap). Therefore, a solvent-free technique was required for RBO extraction. Thus, the cold press extraction method was used to extract RBO. 
Studies on the formulation and stability of the cosmetic products with natural ingredients are insufficient because of the trade secrets and marketing liability of the inventor or company. However, scientific reports on the cosmetic products are mandatory for the development of upgraded cosmetics with naturally available bioactive compounds. Thus, the current study aimed to extract the active principles from purple RB, formulate the cosmetic products, and evaluate the physical property and stability of the products.

\section{METHODS}

Raw materials

The purple rice was collected from local market of Chiang Mai, Thailand, and milled to acquire fresh RB (PRB). The fermented and distilled purple rice solution (FDPRS) was obtained from Health Innovation Institute, Chiang Mai, Thailand.

\section{Extraction}

RBO was extracted by the cold press method as described previously [19]. PRB was subjected to $80 \%$ ethanol extraction as described previously [2]. The extracts were stored at $-20^{\circ} \mathrm{C}$ until analysis.

\section{Assessment of oryzanol, phenolic, and anthocyanin content}

Oryzanol content of RBO was determined by high-pressure liquid chromatography (HPLC) as detailed in the previous publication [19]. Total phenolic and anthocyanin contents of rice extract were analyzed using spectrophotometric methods. The quantification of each phenolic compounds was achieved by HPLC as detailed in the previous publication [2]

\section{Determination of antioxidant capacity}

Antioxidant capacity of RBO, PRE, and FDPRS was assessed by 2, 2'-azino-bis-3-ethylbenzthiazoline-6-sulfonic acid (ABTS), 1, 1-diphenyl-2-picryl-hydrazil (DPPH), and ferric reducing antioxidant power (FRAP), assays as described in our previous reports [2,21].

\section{Formulations}

The mineral spray, shampoo, liquid soap, and solid soap formulations were prepared as detailed in Table 1 . The concentration of each compound is based on the data received from the Health Innovation Institute, Chiang Mai, Thailand (unpublished private data).

\section{Stability study}

Liquid or semi-solid cosmetic formulations such as shampoo, liquid soap, and mineral spray were subjected to cool-heat cycle process to check the stability. The samples were stored at $4 \pm 2^{\circ} \mathrm{C}$ for $48 \mathrm{~h}$ and then transferred to $45 \pm 2^{\circ} \mathrm{C}$ for $48 \mathrm{~h}$. The cycling of cool and heat process was repeated for 6 times. Then, the changes (color and layer separation) in the samples were observed. In another experiment, formulations were stored at different temperatures $\left(4 \pm 2,30 \pm 2\right.$, and $\left.45 \pm 2^{\circ} \mathrm{C}\right)$ for 2 months, and samples were collected every month for the quality evaluation. Color, fragrance, layer separation, and $\mathrm{pH}$ of the products were evaluated, and the total phenolic and oryzanol content of the formulas was measured to check the quality of the product.

\section{Evaluation of heavy metal content}

Lead, arsenic, mercury, and barium content in the cosmetic formulations were determined by atomic absorption spectrometry (Model-932 plus, GBC, Germany) as described in the previous publication [22,23].

\section{Microbial contamination}

The microbiological safety of the products was determined by evaluating the presence of representative microbial pathogens such as Staphylococcus aureus, Escherichia coli, Pseudomonas aeruginosa, and Candida albicans in the product by plate count method as detailed in the previous publication $[24,25]$.

\section{Statistical analysis}

The report of the data was given as mean \pm standard deviation. The Analysis of variance was performed using the statistical SPSS software version 17 (Chicago, SPSS Inc., U.S.A). Duncan's new multiple range tests determined significant differences, at the $95 \%$ confidential level $(\mathrm{p}<0.05)$.

\section{RESULTS AND DISCUSSION}

The PRE and RBO were prepared from fresh RB. The yield of PRE and RBO was 0.92 and $1.62 \%$, respectively (Fig. 1a). Oryzanol content of RBO was observed to be $6.33 \pm 0.09 \mathrm{mg} / \mathrm{g}$ of RBO. The total phenolic and anthocyanin content of PRE was $305.30 \pm 6.15 \mathrm{mg}$ gallic acid/g of extract and $877.33 \pm 87.73 \mathrm{mg}$ cyanidin chloride/g of extract, respectively (Fig. 1b). The phenolic acids were determined by HPLC. Protocatechuic acid, caffeic acid, syringic acid, and $p$-coumaric acid in PRE were quantified, and the concentration was found to be $0.87 \pm 0.04$, $1.02 \pm 0.05,0.20 \pm 0.01$, and $11.40 \pm 0.57 \mathrm{mg} / \mathrm{g}$ of extract, respectively (Fig. 1c). FDPRS was obtained from health innovation institute. Hence, the content of the FDPRS was not determined in the present study.

The antioxidant capacity of RBO was found as $6.25 \pm 0.21 \mathrm{mg}$ trolox/g of RBO extract and $14.94 \pm 1.2 \mathrm{mg} \mathrm{FeSO}_{4} / \mathrm{g}$ of RBO extract in ABTS and

Table 1: The composition of the cosmetic preparations

\begin{tabular}{|c|c|c|c|c|c|c|c|}
\hline \multicolumn{2}{|l|}{ Mineral spray } & \multicolumn{2}{|l|}{ Shampoo } & \multicolumn{2}{|l|}{ Liquid soap } & \multicolumn{2}{|l|}{ Solid soap } \\
\hline Ingredient & Concentration (\%) & Ingredient & Concentration (\%) & Ingredient & Concentration (\%) & Ingredient & Concentration (\%) \\
\hline DEB-96 & 10.00 & $\begin{array}{l}\text { Texapon }^{\circledR} \\
\text { N8000 }\end{array}$ & 30.00 & $\begin{array}{l}\text { Texapon }^{\circledR} \\
\text { N8000 }\end{array}$ & 26.00 & Glycerin & 90.00 \\
\hline Sodium benzoate & 0.02 & $\begin{array}{l}\text { Texapon }{ }^{\circledR} \\
\text { N } 40\end{array}$ & 10.00 & $\begin{array}{l}\text { Texapon }^{\circledR} \\
\text { N } 40\end{array}$ & 17.50 & PRE & 0.10 \\
\hline Copper sulfate & 0.10 & Glydant $^{\mathrm{TM}}$ & 0.25 & $\begin{array}{l}\text { Comperlan }{ }^{\circledR} \\
\text { KD }\end{array}$ & 2.00 & FDPRS & 3.00 \\
\hline Tween-80 & 0.50 & Bronidox $^{\circledR}$ & 0.25 & Allantoin & 0.50 & Water & 5.90 \\
\hline PRE & 0.10 & 10\% EDTA & 1.00 & Glydant $^{\mathrm{TM}}$ & 0.25 & & \\
\hline FDPRS & 10.00 & $\begin{array}{l}\text { Sodium } \\
\text { chloride }\end{array}$ & 2.00 & Bronidox $^{\circledR}$ & 0.25 & & \\
\hline \multirow[t]{4}{*}{ Water } & 79.18 & PRE & 0.10 & $10 \%$ EDTA & 1.00 & & \\
\hline & & Water & 44.40 & PRE & 0.10 & & \\
\hline & & & & FDPRS & 10.0 & & \\
\hline & & & & Water & 39.40 & & \\
\hline
\end{tabular}

PRE: Purple rice bran extract, FDPRS: Fermented and distilled purple rice solution, RBO: Rice bran oil 
FRAP assay, respectively. In DPPH assay, the IC $\mathrm{C}_{50}$ concentration of RBO was $1.52 \pm 0.31 \mathrm{mg}$. The antioxidant capacity of PRE was determined as $24.68 \pm 1.30 \mathrm{mg}$ trolox/g of PRE and $90.14 \pm 1.2 \mathrm{mg} \mathrm{FeSO} / \mathrm{g}$ of PRE in ABTS and FRAP assay, respectively. The $\mathrm{IC}_{50}$ concentration of PRE was $0.71 \pm 0.20 \mathrm{mg}$ in DPPH assay (Table 2). FDPRS showed free radical scavenging property (Table 2 ).

The cosmetic formulations were prepared as detailed in Table 1. Then, the formulations were subjected to stability study. The liquid and semi-liquid products were tested for the ability to withstand the drastic temperature changes by cool-heat cycle method. After three cycles of the cool-heat process, the color of the mineral spray, shampoo, and liquid soap becomes pale than that of its original color (red). The viscosity of the product was not altered, and no layer separation was observed (Table 3). The color of the product changed after three cycles of heating and cooling is due to the changes or deformation of the phytocompounds present in the formulas.

The formulations were stored at different temperatures $(4,30$, and $45^{\circ} \mathrm{C}$ ) for 2 months, and the changes were assessed. The color, fragrance, viscosity, and $\mathrm{pH}$ of the products were not changed, and no layer separation was detected (Table 4).

The degradation profile of active (phenolic) compounds of PRE was assessed when stored at a different temperature. The concentration of protocatechuic acid $(0.87 \pm 0.04$ to $0.91 \pm 0.03 \mathrm{mg} / \mathrm{g}$ extract $)$, caffeic acid $(1.01 \pm 0.05$ to $0.97 \pm 0.01 \mathrm{mg} / \mathrm{g}$ extract), and $p$-coumaric acid $(11.40 \pm 0.57$ to $11.09 \pm 0.53 \mathrm{mg} / \mathrm{g}$ extract) was not significantly altered during storage at $30^{\circ} \mathrm{C}$ for 2 months. There was no alteration observed in the concentration of syringic acid $(0.19 \pm 0.01 \mathrm{mg} / \mathrm{g}$ extract) during storage at $30^{\circ} \mathrm{C}$ for 2 months (Table 5). The non-significant level of reduction in phenolic compounds was observed, which indicated that the PRE is stable for 2 months even when stored at $45^{\circ} \mathrm{C}$.

The phenolic acid content of cosmetic products stored at various temperature was determined to evaluate the stability of active compounds in the cosmetic products. In mineral spray formulation, $29.47 \%$ degradation of phenolic compounds was observed during the storage period ( 2 months) at $45^{\circ} \mathrm{C}$. In shampoo formulation, the

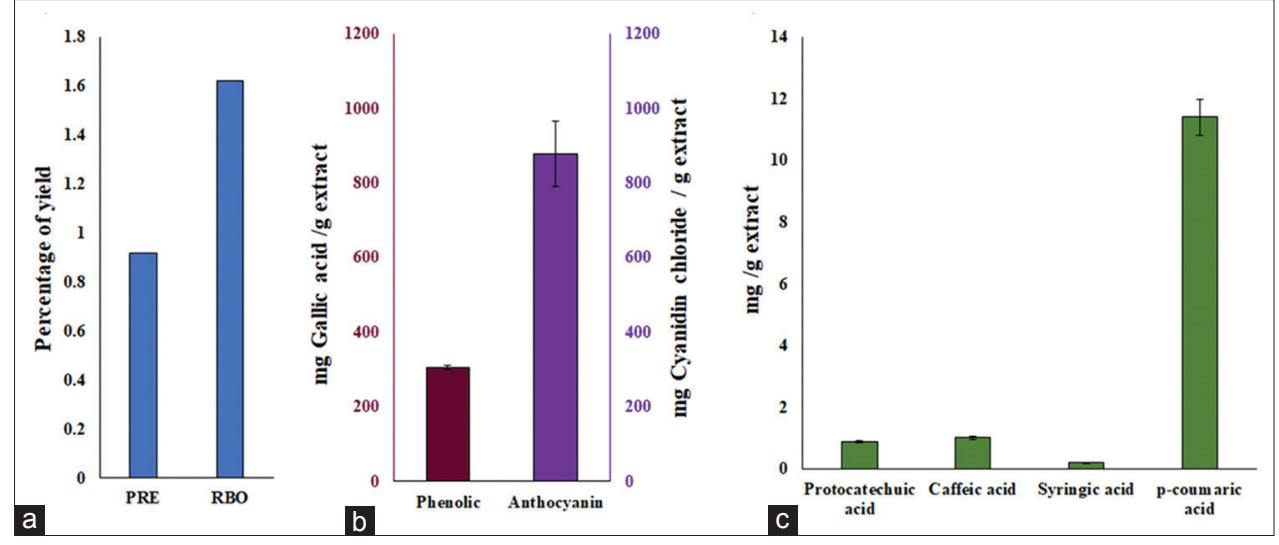

Fig. 1: The yield of purple rice bran extract (PRE) and rice bran oil (a), the phytochemical content of PRE (b), and phenolic acid composition (c) of PRE

Table 2: The antioxidant capacity of PRE, RBO, and FDPRS

\begin{tabular}{llll}
\hline Samples & DPPH assay $\left(\mathbf{I C}_{\mathbf{5 0}}\right)$ & ABTS assay $(\mathbf{m g}$ trolox $/ \mathbf{g}$ or $\mathbf{~ m l ~ e x t r a c t s )}$ & FRAP assay (mg FeSO $_{4} / \mathbf{g}$ or $\mathbf{~ m l ~ e x t r a c t s )}$ \\
\hline PRE & $0.71 \pm 0.20 \mathrm{mg}$ & $24.68 \pm 1.30 \mathrm{mg} / \mathrm{g}$ & $90.14 \pm 1.2 \mathrm{mg} / \mathrm{g}$ \\
RBO & $1.52 \pm 0.31 \mathrm{mg}$ & $6.25 \pm 0.21 \mathrm{mg} / \mathrm{g}$ & $14.94 \pm 1.2 \mathrm{mg} / \mathrm{g}$ \\
FDPRS & $1.25 \pm 1.02 \mathrm{ml}$ & $0.01 \pm 0.00 \mathrm{mg} / \mathrm{ml}$ & $0.07 \pm 0.00 \mathrm{mg} / \mathrm{ml}$ \\
\hline
\end{tabular}

PRE: Purple rice bran extract, FDPRS: Fermented and distilled purple rice solution, RBO: Rice bran oil, DPPH: 1, 1-diphenyl-2-picryl-hydrazil, ABTS: 2, 2'-azino-bis-3ethylbenzthiazoline-6-sulfonic acid, FRAP: Ferric reducing antioxidant power

Table 3: The stability of the cosmetic formulations after cool-heat cycle study

\begin{tabular}{llllll}
\hline Formulation & Color* & & Viscosity** & & Layer separation \\
\cline { 2 - 3 } & $\mathbf{0 - 2}$ cycles & $\mathbf{3 - 6}$ cycles & & $\mathbf{0 - 6}$ cycles & -6 cycles \\
\hline Mineral spray & Red & Lighter & + & No separation \\
Shampoo & Red & Lighter & Lighter & ++ & No separation \\
Liquid soap & Red & +++ & No separation \\
\hline
\end{tabular}

${ }^{*}$ Color of the cosmetic formulations was red during $0-2$ cycles and the color changed to lighter or pale after third cycle; ${ }^{* *}+: 0.69-0.72 \mathrm{mPa} .5 ;++: 990-999 \mathrm{mPa} .5$; +++: 2350-2450 mPa.s

Table 4: The stability of the products stored at 4,30 , and $45^{\circ} \mathrm{C}$ for 2 months

\begin{tabular}{llllll}
\hline Formulation & Color & Fragrance & Viscosity & Layer separation \\
\hline Mineral spray & Red & Mild rice fragrance & + & No separation \\
Shampoo & Red & Mild rice fragrance & ++ & No separation & 5 \\
Liquid soap & Red & Mild rice fragrance & +++ & No separation & 6 \\
Hard soap & Dark red & Mild rice fragrance & - & - & 6 \\
\hline
\end{tabular}

**+: 0.69-0.72 mPa.s; ++: 990-999mPa.s; +++: 2350-2450 mPa.s 
phenolic compounds were degraded up to $29.98 \%$ when stored at $45^{\circ} \mathrm{C}$ for 2 months (Fig. 2). In liquid soap formulation, degradation $(30.03 \%)$ of phenolic compounds was observed when stored at $45^{\circ} \mathrm{C}$ for 2 months. Storage of hard soap at $45^{\circ} \mathrm{C}$ for 2 months results in the degradation (55.43\%) of phenolic compounds (Fig. 3 ).

The phenolic compounds were observed to be stable in the liquid soap formulation when stored at $4^{\circ} \mathrm{C}$ and $30^{\circ} \mathrm{C}$ for 1 -month storage

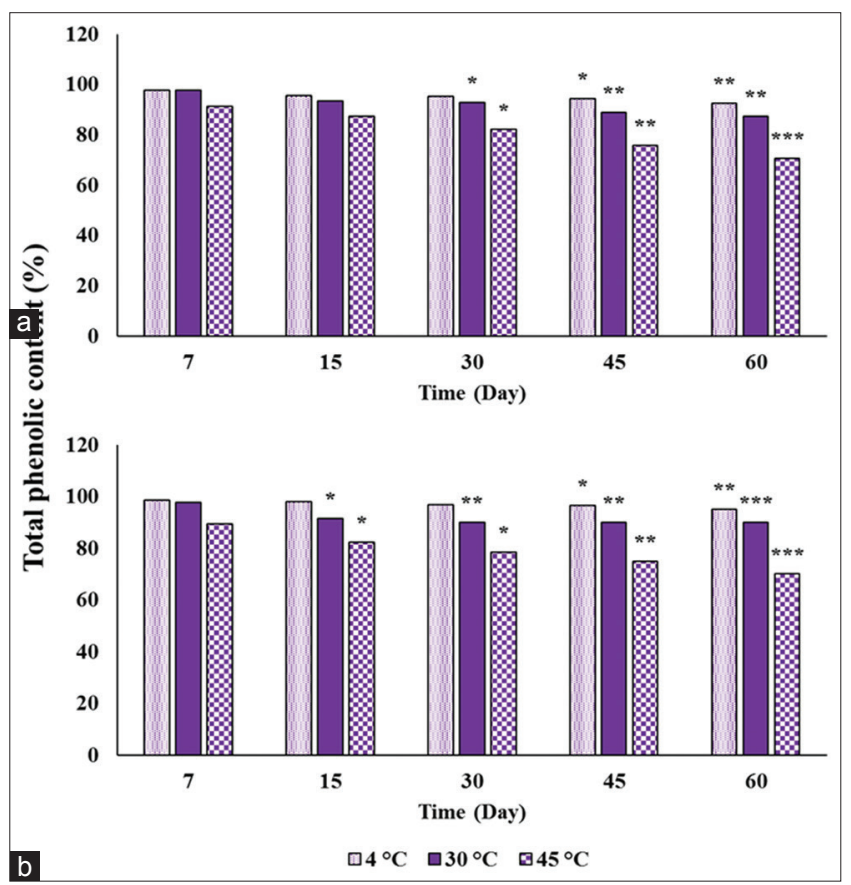

Fig. 2: The changes in the phenolic content of mineral spray (a) and shampoo (b) during storage at different temperature $\left(4^{\circ} \mathrm{C}\right.$, $30^{\circ} \mathrm{C}$, and $\left.45^{\circ} \mathrm{C}\right) .^{*}, * *$, and ${ }^{* * *}$ represent the significant variation with $p>0.05,0.01$, and 0.001 , respectively

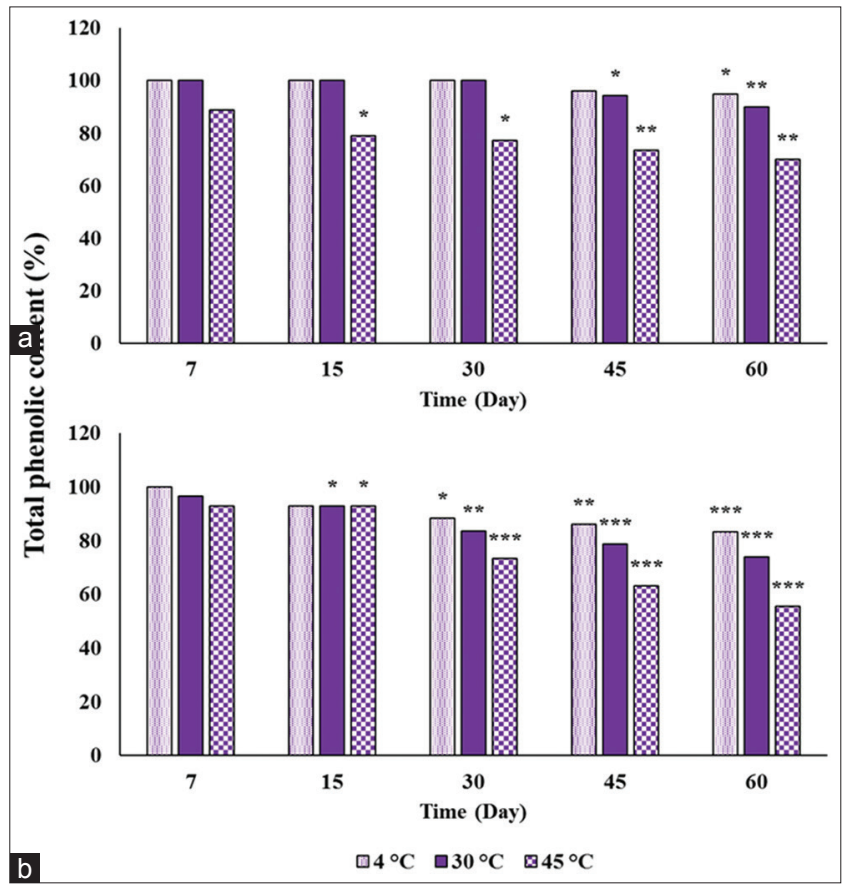

Fig. 3: The changes in the phenolic content of liquid soap (a) and solid soap (b) during storage at different temperature $\left(4^{\circ} \mathrm{C}, 30^{\circ} \mathrm{C}\right.$ and $\left.45^{\circ} \mathrm{C}\right) .^{*}, * *$, and ${ }^{* * *}$ represent the significant variation with p $>0.05,0.01$, and 0.001 , respectively duration and later showed reduction until the end of the experiment (Fig. 3). A significant level of reduction of phenolic compounds was observed in all the formulations while stored at $45^{\circ} \mathrm{C}$ for 2 months, whereas solid soap formulation showed a significant level of degradation $(26.07 \%)$ of phenolic compounds while stored at $30^{\circ} \mathrm{C}$ for 2 months. The main active component of hard soap formula is oryzanol. Thus, the stability of oryzanol was determined and found that no degradation occurred until 15 days of storage at various temperature, whereas extended storage time displayed reduction $\left(2.63,3.62\right.$, and $6.25 \%$ degradation of oryzanol at 4,30 , and $45^{\circ} \mathrm{C}$, respectively) in oryzanol content. The storage temperature $\left(45^{\circ} \mathrm{C}\right)$ triggers the degradation of active compounds present in the cosmetic products (Fig. 4)

The stability study suggested that the storage temperature affects the active compound of the product. The storage at room temperature $\left(30^{\circ} \mathrm{C}\right)$ also influences the phenolic content of the products, especially hard soap is more vulnerable to the temperature. However, the products retain at least $70 \%$ of its active principles, which suggested that the formulation was acceptable for further evaluation and marketing.

The heavy metal contamination in the cosmetic products was also assessed. Lead and barium were found in the mineral spray, shampoo, and soap products. The amount of lead and barium was $<0.13 \mathrm{ppm}$ and $<0.24 \mathrm{ppm}$, respectively, which is an acceptable range of heavy metals in the cosmetics. Hence, all the products passed the heavy metal quality check (Table 6). The cosmetic products were analyzed for the microbiological safety and found that there was no culturable microbial content in the cosmetic samples (Table 7).

The results revealed that the cosmetic products are safe for human use and are free from heavy metal and microbial contamination. The cosmetic products are now intentionally made with natural compounds

Table 5: The stability of purple rice bran extract stored at $30^{\circ} \mathrm{C}$

\begin{tabular}{lllll}
\hline S. No. & $\begin{array}{l}\text { Phenolic } \\
\text { compounds }\end{array}$ & 0 day & 30 days & 60 days \\
\hline 1 & Protocatechuic & $0.87 \pm 0.04$ & $0.89 \pm 0.02$ & $0.91 \pm 0.03$ \\
& acid & $1.01 \pm 0.05$ & $0.99 \pm 0.01$ & $0.97 \pm 0.01$ \\
2 & Caffeic acid & $0.19 \pm 0.01$ & $0.19 \pm 0.00$ & $0.19 \pm 0.01$ \\
3 & Syringic acid & $11.40 \pm 0.57$ & $11.24 \pm 0.52$ & $11.09 \pm 0.53$ \\
4 & $\begin{array}{l}\text { p-coumaric } \\
\text { acid }\end{array}$ & & & \\
\hline
\end{tabular}

The values are represented as mg/g extract \pm SD. SD: Standard deviation

Table 6: The heavy metal contamination in the cosmetic formulas

\begin{tabular}{llll}
\hline Formulas & Heavy metal & Detected value & Result \\
\hline Mineral spray & Lead* & $<0.13$ ppm & Pass \\
& Mercury* & Not detected & Pass \\
& Arsenic* & Not detected & Pass \\
& Barium* & 0.24 ppm & Pass \\
Shampoo & Lead* & Not detected & Pass \\
& Mercury* & Not detected & Pass \\
& Arsenic* & Not detected & Pass \\
& Barium* & 0.16 ppm & Pass \\
Liquid soap & Lead* & Not detected & Pass \\
& Mercury* & Not detected & Pass \\
& Arsenic* & Not detected & Pass \\
& Barium* & $<0.13$ ppm & Pass \\
Hard soap & Lead* & Not detected & Pass \\
& Mercury* & Not detected & Pass \\
& Arsenic* & Not detected & Pass \\
& Barium* & 0.24 ppm & Pass \\
\hline
\end{tabular}

*The acceptable range of lead, mercury, arsenic, and barium are $>20 \mathrm{ppm}$, $>0.5 \mathrm{ppm},>5 \mathrm{ppm}$, and $>500 \mathrm{ppm}$, respectively 


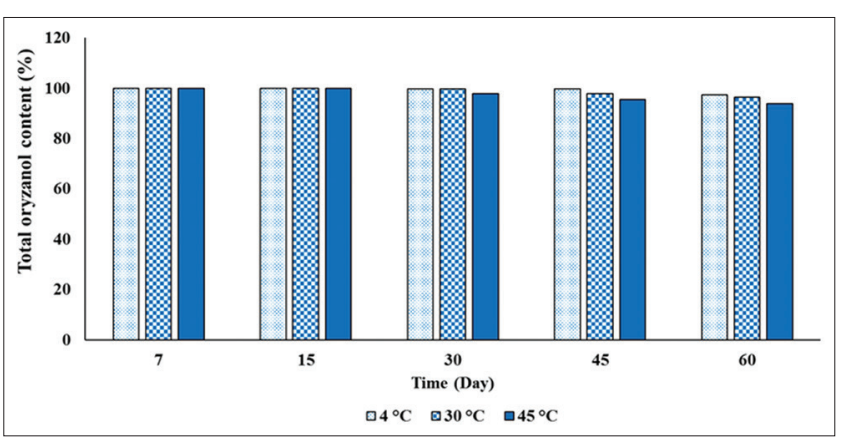

Fig. 4: The changes in the oryzanol content of the solid soap formulations during storage

Table 7: The microbiological analysis of cosmetic formulations

\begin{tabular}{lll}
\hline Formulations & Representative microbes & 0-2 months \\
\hline Mineral spray, & Staphylococcus aureus & Not detected \\
shampoo, liquid & Escherichia coli & Not detected \\
soap, and solid soap & Pseudomonas aeruginosa & Not detected \\
& Candida albicans & Not detected \\
\hline
\end{tabular}

as principal active ingredients. Some of the recent reports demand the use of fermented plant juice and alternative preservatives for the cosmetic preparations [26,27]. The rice and RB-derived compounds are used in cosmetic products, especially in moisturizer and skin care products $[12,14]$.

Hanno et al. [15] reported the use of a rice-derived natural surfactant with emulsifying properties as a green cosmetic approach. In vitro cytotoxicity test and experiments in human volunteers proved that the rice panicle extract contains high levels of phenolic compounds, which provides the nourishment and acted as a skin antiaging agent [28]. Manosroi et al. reported that the RB bioactive compounds exhibit antiaging property while entrapped in niosomes. The results also proved that the formulation was a potent and novel skin care product [14].

\section{CONCLUSION}

The current study was a novel attempt to develop cosmetic products with PRE and RBO. Moreover, the present study also uses the fermented rice juice as a source of bioactive principle. We have already reported the use of fermented plant juice in cosmetic products [26]. The results of the current study suggested that the rice phytochemical-based cosmetic products are stable, free from heavy metals, and microbial contamination, and further fine-tuning of the formulation is needed to meet the market quality.

\section{ACKNOWLEDGMENT}

Authors gratefully acknowledge the Chiang Mai University grant (CMU-grant) for the support. Authors also acknowledge the Faculty of Pharmacy, and Chiang Mai University, Thailand, for the necessary provision.

\section{REFERENCES}

1. Milam EC, Rieder EA. An approach to cosmeceuticals. J Drugs Dermatol 2016;15:452-6.

2. Pengkumsri N, Chaiyasut C, Saenjum C, Sirilun S, Peerajan S, Suwannalert $\mathrm{P}$, et al. Physicochemical and anti-oxidative properties of black, brown and red rice varieties of northern Thailand. Food Sci Technol (Campinas)2015;35:331-8

3. Pengkumsri N, Sivamaruthi BS, Sirilun S, Suwannalert P, Rodboon T, Prasitpuriprecha $\mathrm{C}$, et al. Dietary supplementation of Thai black rice bran extract and yeast beta-glucan protects the dextran sodium sulphate mediated colitis induced rat. RSC Adv 2017;7:396-402.
4. Marko D, Puppel N, Tjaden Z, Jakobs S, Pahlke G. The substitution pattern of anthocyanidins affects different cellular signaling cascades regulating cell proliferation. Mol Nutr Food Res 2004; $48: 318-25$.

5. Chaiyasut C, Sivamaruthi BS, Pengkumsri N, Keapai W, Kesika P, Saelee M, et al. Germinated thai black rice extract protects experimental diabetic rats from oxidative stress and other diabetesrelated consequences. Pharmaceuticals (Basel)2016;10. pii: E3.

6. Canter PH, Ernst E. Anthocyanosides of Vaccinium myrtillus (bilberry) for night vision-a systematic review of placebo-controlled trials. Surv Ophthalmol 2004;49:38-50.

7. Lau FC, Shukitt-Hale B, Joseph JA. Nutritional intervention in brain aging: Reducing the effects of inflammation and oxidative stress. In: Harris RE, editor. Inflammation in the Pathogenesis of Chronic Diseases. New York: Springer; 2007. p. 299-318

8. Settharaksa S, Madaka F, Charkree K, Charoenchai L. The study of anti-inflammatory and antioxidant activity in cold press rice bran oil from rice in Thailand. Int J Pharm Pharm Sci 2014;6:428-31.

9. Choi JS, Jeon MH, Moon WS, Moon JN, Cheon EJ, Kim JW, et al. In vivo hair growth-promoting effect of rice bran extract prepared by supercritical carbon dioxide fluid. Biol Pharm Bull 2014;37:44-53.

10. Choi JS, Park JB, Moon WS, Moon JN, Son SW, Kim MR. Safety and efficacy of rice bran supercritical $\mathrm{CO}_{2}$ extract for hair growth in androgenic alopecia: A 16-week double-blind randomized controlled trial. Biol Pharm Bull 2015;38:1856-63.

11. Miyazawa M, Oshima T, Koshio K, Itsuzaki Y, Anzai J. Tyrosinase inhibitor from black rice bran. J Agric Food Chem 2003;51:6953-6.

12. Choi SP, Kim SP, Kang MY, Nam SH, Friedman M. Protective effects of black rice bran against chemically-induced inflammation of mouse skin. J Agric Food Chem 2010;58:10007-15.

13. Bernardi DS, Pereira TA, Maciel NR, Bortoloto J, Viera GS, Oliveira GC, et al. Formation and stability of oil-in-water nanoemulsions containing rice bran oil: In vitro and in vivo assessments. J Nanobiotechnology 2011;9:44.

14. Manosroi A, Chutoprapat R, Abe M, Manosroi W, Manosroi J. Antiaging effect of topical formulations containing niosomes entrapped with rice bran bioactive compounds. Pharm Biol 2012;50:208-24.

15. Hanno I, Centini M, Anselmi C, Bibiani C. Green cosmetic surfactant from rice: Characterization and application. Cosmetics 2015;2:322-41.

16. Vichit W, Saewan N. Antioxidant activities and cytotoxicity of Thai pigmented rice. Int J Pharm Pharm Sci 2015;7:329-34.

17. Daud NS, Zaidel DN, Song LK, Muhamad II, Jusoh YM. Antioxidant properties of rice bran oil from different varieties extracted by solvent extraction methods. J Teknol (Sci Engn) 2016;78:107-10.

18. Sukrasno S, Tuty S, Fidrianny I. Antioxidant evaluation and phytochemical content of various rice bran extracts of three varieties rice from Semarang central Java, Indonesia. Asian J Pharm Clin Res 2017; 10:377-82.

19. Pengkumsri N, Chaiyasut C, Sivamaruthi BS, Saenjum C, Sirilun S, Peerajan $\mathrm{S}$, et al. The influence of extraction methods on composition and antioxidant properties of rice bran oil. Food Sci Technol (Campinas)2015;35:493-501

20. Matouk AM, El-Kholy MM, El-Sadany M, Hendawy YT. Rice bran oil extraction using an expeller machine. Misr J Agric Eng 2009;26:324-42.

21. Chaiyasut C, Pengkumsri N, Sirilun S, Peerajan S, Khongtan S, Sivamaruthi BS. Assessment of changes in the content of anthocyanins, phenolic acids, and antioxidant property of Saccharomyces cerevisiae mediated fermented black rice bran. AMB Express 2017;7:114

22. Chaiyasut C, Sivamaruthi BS, Peerajan S, Sirilun S, Chaiyasut K, Kesika P. Assessment of heavy metals, minerals, alcohol, and fusel oil content of selected fermented plant beverages of Thailand. Int Food Res J 2017;24:126-33

23. Horwitz W. Official Methods of Analysis of AOAC International. Vol. 1. Gaithersburg, MD: AOAC International; 2000.

24. Pattananandecha T, Sirilun S, Duangjitcharoen Y, Sivamaruthi BS, Suwannalert P, Peerajan S, et al. Hydrolyzed inulin alleviates the azoxymethane-induced preneoplastic aberrant crypt foci by altering selected intestinal microbiota in Sprague-Dawley rats. Pharm Biol 2016;54:1596-605.

25. Chaiyasut C, Pattananandecha T, Sirilun S, Suwannalert P, Peerajan S, Sivamaruthi BS. Synbiotic preparation with lactic acid bacteria and inulin as a functional food: In vivo evaluation of microbial activities, and preneoplastic aberrant crypt foci. Food Sci Technol (Campinas)2017;37:328-36.

26. Sirilun S, Sivamaruthi BS, Kumar N, Kesika P, Peerajan S, Chaiyasut C. Lactobacillus-fermented plant juice as a potential ingredient in 
cosmetics: Formulation and assessment of natural mouthwash. Asian J Pharm Clin Res 2016;9 Suppl 3:52-6.

27. Sirilun S, Chaiyasut C, Sivamaruthi BS, Peerajan S, Kumar N, Kesika P. Phenethyl alcohol is an effective non-traditional preservative agent for cosmetic preparations. Asian J Pharm Clin Res 2017;10:129-33.

28. Kanlayavattanakul M, Lourith N, Chaikul P. Jasmine rice panicle: A safe and efficient natural ingredient for skin aging treatments. J Ethnopharmacol 2016;193:607-16. 